\title{
Interview with Dr. Abraham Morgentaler
}

\author{
Abdulmaged Traish ${ }^{1}$ and Abraham Morgentaler ${ }^{2}$
}

\begin{abstract}
Dr. Abdulmaged Traish: Dr. Morgentaler, on behalf of Androgens: Clinical Research and Therapeutics, thank you for joining me today. As the founding President of the Androgen Society, please tell us about yourself as a researcher and physician.
\end{abstract}

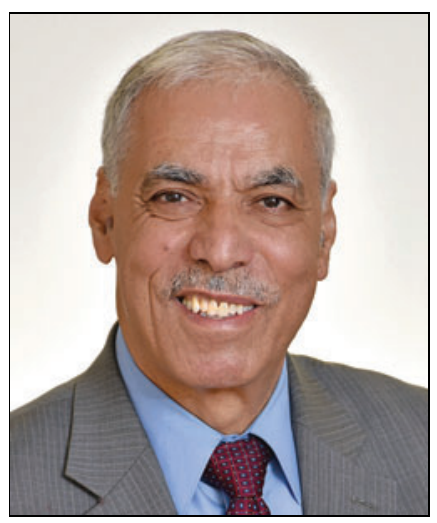

Abdulmaged Traish
Dr. Abraham Morgentaler: Thank you very much for this opportunity to discuss the Androgen Society. My own story is that I have been involved with testosterone research going back to the mid-1970s when I worked in the laboratory of Dr. David Crews for three years studying the effects of testosterone on the sexual behavior of the American chameleon, Anolis carolinensis.

The research was fascinating. The male lizards normally exhibit their sexual behavior when placed in a cage with a female, which consists of extending a brightly colored flap of skin under their jaw, called a dewlap, and performing a series of rapid head bobs. If the animal's testicles are removed, eliminating nearly all testosterone, the lizard stops exhibiting this sexual behavior.

From previous work in the lab, it was known that a subcutaneous testosterone pellet could restore sexual behavior, but my project was more ambitious-namely, to place minute amounts of testosterone directly into the sexual centers of the brain to see what happened. When I successfully placed testosterone into the anterior hypothalamus and the medial preoptic area, it restored the entire range of sexual behavior, including mating,

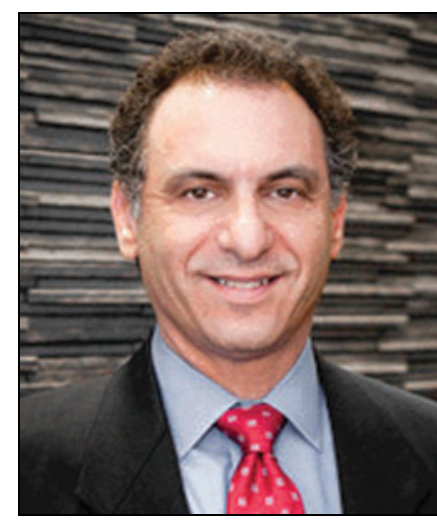

Abraham Morgentaler in those castrated males, despite undetectable serum concentrations of testosterone. The lesson was that testosterone was a brain hormone, and it was a critical regulator of sexual behavior in the male lizard.

I did not learn much about testosterone in medical school or in training, but when I started my career as faculty at Beth Israel Hospitalnow Beth Israel Deaconess Medical Center-and Harvard Medical School, I soon specialized in male reproductive and sexual problems, and decided to try testosterone therapy in men. At that time, the late 1980 s, testosterone use was rare, and exclusively reserved for men with pituitary or hypothalamic tumors, often after resection of those tumors, occasionally in genetic cases, and in men who had lost their testicles either to cancer or to trauma.

At that time, it was simply not recognized that an otherwise healthy man might have low levels of testosterone that could impact his sexual abilities and make him feel poorly. When I started obtaining serum testosterone levels in symptomatic men, I was surprised at how often I found low levels. Because of my experience with lizards, I tried treating some of these men with testosterone, and they did well. Those positive responses by my patients set me off on my career, studying these men, making sure I wasn't precipitating aggressive prostate cancers, and my research and clinical practice using

\footnotetext{
${ }^{1}$ Professor of Biochemistry, Professor of Urology, Boston University School of Medicine, Boston, Massachusetts.

${ }^{2}$ President, Androgen Society, Associate Professor of Urology, Men's Health Boston, Beth Israel Deaconess Medical Center, Harvard Medical School, Boston, Massachusetts.

(c) Abdulmaged Traish and Abraham Morgentaler 2020; Published by Mary Ann Liebert, Inc. This Open Access article is distributed under the terms of the Creative Commons License (http://creativecommons.org/licenses/by/4.0), which permits unrestricted use, distribution, and reproduction in any medium, provided the original work is properly cited.
} 
testosterone therapy has been a central part of my career over the last 30 years.

Dr. Traish: That is very enlightening. Could you tell us a little bit about what prompted you and your colleagues to form the Androgen Society?

Dr. Morgentaler: The Androgen Society was born out of a crisis. For 10-15 years, there had been growing research and clinical experiences showing important health and symptomatic benefits of testosterone therapy in testosterone-deficient men, and many clinicians were gaining confidence treating men and remarking on its benefits. Suddenly, in 2013, an article by Vigen et al. ${ }^{1}$ was published in The Journal of the American Medical Association that alleged increased cardiovascular risks with testosterone therapy, including stroke, heart attack, and death. Although the study contradicted approximately 20 years of medical literature and science, it received enormous media attention and scared many of our patients, many of whom discontinued treatment, even though they had benefitted tremendously from testosterone therapy. The medical community saw the headlines and quickly came to believe testosterone posed major cardiovascular risks.

Given what we knew about testosterone, those results didn't make sense, and it turned out the study was poorly done. Eventually, it came to light that the authors had misreported their original results, and that nearly $10 \%$ of the supposedly all-male population turned out to be female. This was not a credible article.

To educate physicians and the public regarding the truth about testosterone, a group of us consisting of you, Andre Guay, Martin Miner, Mohit Khera, and I formed the Androgen Study Group, and we did a deep dive into the cardiovascular issues, publishing a major review in Mayo Clinic Proceedings. ${ }^{2}$

That experience with a multidisciplinary group of urologists, an endocrinologist, family medicine physician, and steroid biochemist led in turn to an international expert consensus meeting that was held in Prague in 2015. For the first time, at least in my experience in the testosterone world, experts from around the world from multiple relevant disciplines got together not to disagree with each other, as we often do at academic meetings, but rather to find a common ground. We were able to agree unanimously on a set of fundamental concepts about testosterone deficiency and its treatment.

That meeting was an amazing experience. The level of knowledge and discussion was at such a high level that several of us came away thinking that it would be a tremendous service to the scientific community, and certainly to our colleagues interested in testosterone, if we could create a society that replicated the key features of that meeting-multidisciplinary, international, bringing together various perspectives, and challenging each other to find common ground or to defend individual positions in an academically respectful way. That meeting led directly to the genesis of the Androgen Society.

Dr. Traish: To follow up on that, what are some of the challenges that you encountered during the formation or creation of the Androgen Society?

Dr. Morgentaler: Because the Androgen Society brings together researchers and clinicians from a variety of medical disciplines, the most challenging part of getting the society off the ground was political. Any number of existing organizations already claim to offer platforms where issues related to testosterone are presented, and they saw the Androgen Society competitively. "Why do you need another society? We are already the experts in that area."

And this has been the problem with testosterone research and education to date. While it is true that many societies cover testosterone-related issues to a degree, there is no society that does so in depth, year after year. Moreover, every discipline operates within its own silo-urologists attend urology meetings, endocrinologists go to endocrinology meetings, and so forth, and there is little opportunity for exchange of ideas. Anyone interested in testosterone research and clinical practice will be blown away by the depth and breadth of what is offered at the annual meeting of the Androgen Society. There is simply nothing else like it in the world.

Dr. Traish: To follow up on that, what is the most important unmet need that the society wishes to fill?

Dr. Morgentaler: The biggest reason for the society to exist is to address the big gap, which is to get everybody together, including endocrinologists and urologists and public health and experts from all these different disciplines, so that they can discuss new science, discuss attitudes and philosophies about treatment, and share their knowledge. Until today, there has not been a single platform for that to happen, and the Androgen Society fulfills that need.

Dr. Traish: That is great. So, there are multiple disciplines in medicine, but the question is why would 
someone from internal medicine or from hematology want to join the Androgen Society or attend an annual meeting?

Dr. Morgentaler: There are two excellent reasons to attend our meeting. One is that this is the premier meeting in the world for testosterone-related topics. Testosterone has such broad pleotropic effects that to study one narrow area is like the tale of the blind men feeling an elephant and trying to describe what it is. One may feel the trunk, one the tail, another a tusk, and none of them will have a sense of the whole animal. That big picture is what the Androgen Society offers. We deal with diverse topics that range from prostate cancer to cardiovascular issues, obesity, diabetes, and even dry eyes. There is no other meeting or organization like this in the world.

The second reason is to meet like-minded individuals who share an interest in the field. Many individuals who are doing research or clinical work in this area feel alone. It is incredible to meet and interact with people with similar interests, not only for general knowledge and a sense of community, but, even more importantly, for research collaborations. One of the highlights of our last meeting for me was just seeing the groups of people who had never met before, sharing data and discussing plans for new collaborations.

Dr. Traish: Just to build on your last comment, there is the Endocrine Society, the American Urological Association, the American Society of Andrology, the Sexual Medicine Society, et cetera. What would a physician gain by attending the Androgen Society meeting in addition to or rather than a meeting of any of those other societies?

Dr. Morgentaler: The Androgen Society provides an unparalleled deep dive into the world of testosterone deficiency and its treatment and related topics. I am not aware of any other meeting that provides the level of depth and breadth of coverage and expertise.

In addition, it happens to be an unfortunate fact that each medical discipline has a set of philosophies and practices that may be blindly accepted within their discipline but which differ in important ways by experts from another discipline. One of the most enjoyable sessions at each of our meetings is the clinical case discussions with a panel of experts from different countries and specialties. The panel is presented with several clinical cases to see how each of these specialists approaches diagnosis, evaluation, treatment, and monitoring. They challenge each other, and often the questions from the audience are also challenging. I think we gain something extremely valuable in that endeavor.

Dr. Traish: This brings me to something really interesting. Testosterone use has been around for more than 80 years; it started in the 1930s. So, why did it take so long to form a society focused on testosterone?

Dr. Morgentaler: I think part of the answer is that testosterone has always been regarded with suspicion, particularly claims about what may be called rejuvenation. While any clinician who has treated a modest number of cases will have had patients who report feeling younger, stronger, more alive, and certainly more sexual, those types of claims evoke a strong negative reaction among many physicians, to the point where testosterone deficiency and its treatment has never been blessed by the mainstream medical community and, to this day, is not a part of the medical school curriculum. Only recently has the evidence demonstrating the negative impact of testosterone deficiency on health and quality of life become so overwhelming that testosterone therapy is now becoming more broadly accepted, albeit still with a hefty dose of suspicion.

Another reason is that testosterone research was indeed being performed, presented, and published, but this was done in specialty meetings without interactions between different groups. Urologists, for example, just do not attend endocrinology meetings, and vice versa.

Dr. Traish: I am going to turn to a different set of issues now. The media always paints testosterone as an evil of some sort and use of testosterone as a dangerous thing. In your view, what are some of the common misconceptions about testosterone deficiency and testosterone therapy?

Dr. Morgentaler: Testosterone has really suffered from being a term that people use in everyday life as if they know what testosterone is, even if they do not, so that when we talk about stock traders getting excited, we talk about their testosterone rising, when in fact, we have no idea if that is true. We talk about malemale competition and aggression all being fueled by testosterone.

And there is a sense that everybody knows about testosterone, and for the most part, what they know about it is negative. That perspective is made even worse by 
ads that we see on TV or in the media that promote supplements that are, I suppose, allegedly intended to boost testosterone, to make men more "manly."

And then finally, there is another area in which it is known that athletes and body builders have cheated using anabolic steroids to become stronger, add muscle bulk, et cetera, and all of this has a feel of something that is sleazy and improper. And the problem is that there really is a medical condition called testosterone deficiency, or hypogonadism, and it can affect not only the health but also the quality of life of many affected men and women.

Dr. Traish: That brings me to how, even today, testosterone used in the clinical setting remains controversial. Why is that?

Dr. Morgentaler: I think there are three answers to that question. For the longest time, it was simply not believed that testosterone therapy could really help people or improve symptoms or health in men who were testosterone deficient. Critics or skeptics would say, "Okay, there may be some small studies, but show me where there is evidence from a large, randomized controlled trial that testosterone really does something."

In 2016, that gap in the literature was solved by publication of the testosterone trials in The New England Journal of Medicine ${ }^{3}$ and showed with a large, multicenter, controlled prospective trial that testosterone had important benefits for sexuality and for several other features, including not only sexual function, but also bone health, physical activity, and mood. That is number 1 .

Number 2, there have been concerns about prostate cancer going back almost 80 years, and also concerns about cardiovascular risk. Both of those items have made it challenging for the average physician to decide that it is worth treating somebody because we are all afraid of risks. And the good news is that on balance, these issues have been well studied, and the weight of evidence indicates that testosterone does not increase the risk of prostate cancer and does not increase cardiovascular risk.

Dr. Traish: Please explain the terms "hypogonadism" and "testosterone deficiency," and how they differ. The Food and Drug Adminstration uses the term "hypogonadism," yet the Androgen Society favors the term "testosterone deficiency." Why? Are there any really serious differences in these terms and, if so, what are the differences? Otherwise, what should we use, and what do you prefer to use for what we call low testosterone or testosterone deficiency?

Dr. Morgentaler: Until recently, the universal term was "hypogonadism." It has been around for hundreds of years, even before we were able to measure testosterone levels in men. And basically, if you break it down, "hypo-" means low, and "-gonadism" refers to the gonads, which in the male are the testes. So, hypogonadism in men literally indicates under-functioning of the testicles. The definition of hypogonadism includes inadequate testosterone production together with subfertility. In practice, however, we are generally dealing with men in their middle years and older men who have symptoms related to low testosterone levels, yet their fertility is not a concern. Nor do we routinely obtain a semen analysis in these men. This makes the term "hypogonadism" awkward. Is it hypogonadism if a man has infertility but normal serum testosterone, or if he has low testosterone but normal sperm values? It's confusing. A number of terms have been proposed and used to overcome this, but the simplest and clearest is testosterone deficiency. That's what the men present with, that's what we can document and measure, and that's what we treat.

Dr. Traish: Going forward, what do you see as the greatest challenges facing the field of testosterone deficiency and testosterone therapy?

Dr. Morgentaler: There is still an enormous lack of awareness in the medical community of the importance of testosterone deficiency in men-and also in womenin terms of how it impacts general health, and also symptoms that impact quality of life. I see a tremendous need for increased education and awareness around those issues.

Dr. Traish: And as a researcher and practitioner, what do you believe have been the greatest achievements in the field over the last two decades?

Dr. Morgentaler: The publication of the initial results of the Testosterone Trials in 2016 was a seminal moment for the field. Until then, there had been a routine criticism that the risks and benefits of testosterone therapy had never been demonstrated in a large, prospective, multicenter, controlled trial. The Testosterone Trials was exactly such a study, investigating 790 men aged $\geq 65$ years, who received one year of either 
testosterone gel or placebo gel. The Testosterone Trials demonstrated clear benefits and an excellent safety profile, and eliminated the argument that testosterone therapy lacked supporting evidence at the level we have come to expect in medicine.

The second big achievement has been the evolution in our understanding of testosterone and prostate cancer. From the 1940s until today, there has been a tremendous fear that testosterone caused aggressive prostate cancer or would convert a small, quiescent prostate cancer into a dangerous one. This turned out to be incorrect. I would argue that introduction of the saturation model, which you and I described more than 10 years ago, provided the theoretical framework to change those long-standing fears, explaining why there is a real but limited ability of androgens to stimulate prostate cancer, and that the limit, or saturation point, occurs at a low concentration of testosterone. Today, many clinicians offer testosterone therapy to men with a history of prostate cancer after successful surgery or radiation-something considered inconceivable $10-15$ years ago.

Dr. Traish: One final question, but this question is loaded. Put your future glasses on and tell me what do you expect will happen in this field 10, 20, 30 years from now?

Dr. Morgentaler: My prediction is that in 20-30 years, the world of medicine will have come to appreciate fully the impact of testosterone deficiency on the quality of our lives and on our health. The subject will be taught in all medical schools and relevant residency programs, and affected men and women will receive appropriate therapies. And I have no doubt that people will be healthier and happier long into their lives.

Dr. Traish: Well, Dr. Morgentaler, I really want to thank you for a great in-depth interview regarding the topic of testosterone deficiency and its treatment, and look forward to the incredible work coming ahead from the Androgen Society and the entire field of testosterone. Thank you.

Dr. Morgentaler: Thank you very much, and congratulations and good luck in your new position as editorin-chief of the new journal, Androgens: Clinical Research and Therapeutics.

Dr. Traish: It is going to be an exciting time. Looking forward to seeing what comes.

\section{References}

1. Vigen $\mathrm{R}$, $\mathrm{O}$ 'Donnell $\mathrm{Cl}$, Barón $\mathrm{AE}$, et al. Association of testosterone therapy with mortality, myocardial infarction, and stroke in men with low testosterone levels. JAMA 2013;310:1829-1836.

2. Morgentaler A, Miner MM, Caliber $M$, et al. Testosterone therapy and cardiovascular risk: advances and controversies. May Clin Proc 2015; 90: 224-251.

3. Snyder PJ, Bhasin S, Cunningham GR, et al. Effects of testosterone treatment in older men. New Engl J Med 2016; 374: 611-624.

Cite this article as: Traish A, Morgentaler A (2020) Interview with Dr. Abraham Morgentaler, Androgens: Clinical Research and Therapeutics 1.1, 3-7, DOI: 10.1089/andro.2020.29000.int.
Publish in Androgens: Clinical Research and Therapeutics

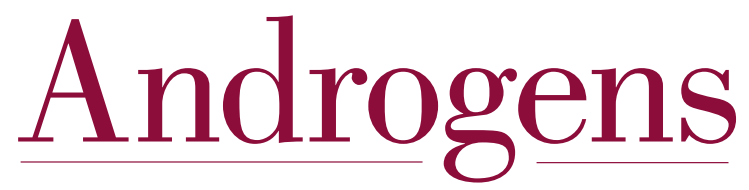

Clinical Research and Therapeutics 